\title{
Isoionic Isotope Exchange with Hydroxylapatite and the Dilution Effect*
}

\author{
Dwarika Nath Misra \\ American Dental Association Health Foundation, Research Unit at the National Bureau of Standards, \\ Washington, DC 20234
}

\begin{abstract}
May 9, 1979
Isoionic isotope exchange data of ${ }^{45} \mathrm{Ca}^{2+}$ and ${ }^{32} \mathrm{PO}_{4}{ }^{3-}$ in a saturated solution with hydroxylapatite at $25{ }^{\circ} \mathrm{C}$, collected by Avnimelech, have been reinterpreted on the basis that the processes consisted of three pools: hydration shell, surface layer and "recrystallization of crystallites." These processes are regarded as strictly separable. This theoretically allows: (i) a quantitative evaluation of the constants involved in the processes; (ii) an estimation of the exchange capacities of hydration and surface layers (fast pools) which may be $\mathrm{pH}$-dependent; and (iii) a determination of the isoionic exchange rate constants. The constants are essentially the same for $\mathrm{Ca}^{2+}$ and $\mathrm{PO}_{4}{ }^{3-}$ at a given $\mathrm{pH}$ if the cross-sectional areas of the ions are taken as $23 \AA^{2}$ and $33 \AA^{2}$ respectively; they, perhaps, increase linearly with the hydrogen ion concentration of the solutions.

The effects of three consecutive abrupt dilutions of the radioactive ions without changing the concentrations (or $\mathrm{pH}$ ) of the nonradioactive components of the solution are predictable by a mathematical model based on the complete reversibility of the two fast pools and the kinetics of the irreversible third pool.
\end{abstract}

Key words: Dilution effect, at same $\mathrm{pH}$ and concentration; hydration shell, role of; hydroxylpatite, at different $\mathrm{pHs}$; isotopic exchange, isoionic; recrystallization, role of; surface layer, role of.

\section{Introduction}

The determination of the isoionic isotope exchange rates of ${ }^{45} \mathrm{Ca}^{2+}$ and ${ }^{32} \mathrm{PO}_{4}{ }^{3-}$ in a saturated solution with hydroxylapatite ("bone mineral", OHAp) may have some fundamental role in understanding the growth, dissolution, adhesion mechanisms and calcium and phosphate homeostasis of bone and tooth tissues. An adequate experimental study with proper theoretical understanding of the exchange mechanism should also throw some light on the surface chemistry of hydroxylapatite which is of immense importance in the fields of mineral processing and agriculture in addition to dental and medical research.

Exchange experiments have been carried out by a number of investigators [1-6]. ${ }^{1}$ In some cases, the studies were conducted under conditions where other interactions such as dissolution, precipitation and hydrolysis were also present and, therefore, in such cases the application of exchange kinetics is evidently not valid. We have chosen to reinterpret the data collected by Avnimelech [4-7]. These experiments were performed under the conditions of saturation at various hydrogen ion concentrations at $25^{\circ} \mathrm{C}$ using a homogeneous

\footnotetext{
${ }^{1}$ Figures in brackets refer to literature references at the end of this paper.

* This investigation was supported, in part, by Research Grant R01 DE05129-01 to the American Dental Association Health Foundation from the National Institutes of Health-National Institute of Dental Research, and is part of the dental research program conducted by the National Bureau of Standards in cooperation with the American Dental Association Health Foundation.
}

nonlabile solid phase which was stabilized by prolonged boiling. We have treated Avnimelech's full data, although partial treatments have been reported [4, 7].

Various theoretical models have been proposed to explain the kinetics of the isoionic exchange process with hydroxylapatite. In general, the isoionic exchange is assumed to comprise three $[1,4,91]$ or more $[3,8]$ processes, each characterized by definite kinetic and capacitative properties. All models contained two pools, hydration shell and surface layer. The third irreversible pool, "recrystallization process," may, however, not be unique and may itself be composed of two or more pools depending upon the exposed crystallographic faces and their energies, etc. Loebenstein's treatment [7] is unique. He interpreted the exchange process on the basis of Langmuir kinetics for the adsorption of a component from solution by a reversible and an irreversible process, simultaneously. Loebenstein's approach is valid, but an explicit correlation between the assumed adsorption and the actual exchange is best approximated only during the early stages.

Treatment of the isoionic exchange by a three-pool process, which we have adopted here, was first considered by Neuman et al. [1] The exchange times for the experiments considered here were generally less than three hours; it is possible that four or more pool processes might have to be invoked for longer time intervals. Our approach is different from others in that we consider the pool processes as 
theoretically separable. This allows us to determine quantitatively the capacities of all three processes and the kinetics of the two. The exchange rate constants and the capacities of the various pools depend on the hydrogen ion concentrations of the solutions. The correlation is, however, not very good and it may be attributed to variable contamination of the surface layers of hydroxylapatite resulting in its incongruent dissolution $[10,11]$ where $\mathrm{Ca}$ to $\mathrm{P}$ ratio in solution is not $5 / 3$.

Based on our mathematical model, we have been able to predict the effect of three consecutive dilutions of the radioactive ions. In the dilution process, the concentration or the $\mathrm{pH}$ of the nonradioactive component is not changed. The predictions are generally very good for the first dilutions. For the second and third dilutions, where the errors become cumulative, the predictions are fair and within the limits of experimental deviations of up to 10 and 20 percent respectively.

\section{Experimental}

The details of the preparation [10] and the experimental procedures [4] have been described by Avnimelech. The hydroxylapatite was prepared by titrating a calcium hydroxide slurry at boiling temperature with phosphoric acid in a $\mathrm{CO}_{2}$-free environment. The resultant precipitate was stabilized by prolonged boiling to minimize recrystallization during the subsequent equilibrations and characterized by $\mathrm{X}$-ray, infrared, and chemical analyses. Its $\operatorname{BET}\left(\mathrm{N}_{2}\right)$ surface area was $26.4 \mathrm{~m}^{2} / \mathrm{g}$.

\section{Results}

Seven sets of exchange experiments at $25{ }^{\circ} \mathrm{C}$ (table 1), differing from one another in slurry density of hydroxylapatite, initial concentration of radioactive tracer ions $\left(i_{0}\right)$, hydrogen ion concentration (and, therefore, in $\mathrm{Ca}^{2+}$ and $\mathrm{PO}_{4}{ }^{3-}$ concentrations), volume of solution, times and fre- quency of sampling and time and amount of dilution, are examined. The value of solubility product $\left(K_{s}\right)$ determined for various runs varies a little. This variation may, however, be well within the limits of the incongruent dissolution [10, 11] of hydroxylapatite. The exchange data for the runs IE10, IE8 and IE13 reproduced here have been reported by Avnimelech [4] and quoted by Loebenstein [7]. The exchange kinetics, including the dilution effect, for two other runs determined by Avnimelech, IE14 and IE15, are presented in figure 1 for ${ }^{45} \mathrm{Ca}^{2+}$ and in figure 2 for ${ }^{32} \mathrm{PO}_{4}{ }^{3-}$.

The exchange curves for all sets have three common features: (i) a precipitous initial fall within one or two minutes, followed by (ii) a gradual decline for up to half an hour, and culminating in (iii) a very slow decrease in activity for the observational period of up to four hours. For the dilution effect, the initial drop in activity in the solution is vertical, followed by a slow rise and eventually ending in a plateau.

\section{Discussion}

It seems reasonable $[1,2]$ to associate the features of the exchange curves with the physical processes that may be occurring in the system. The initial precipitous drop is usually attributed to extremely rapid diffusion between the bulk solution and hydration shell; the intermediate decline in activity is thought to be linked to the surface exchange of ion; $[12,13]$ and, finally, the very slow decrease may be connected with the slow incorporation of ions into the body of crystallites which may be primarily due to the recrystallization processes $[1,3,9]$. To facilitate an analysis of the exchange kinetics, we consider the pool processes as theoretically separable since the first process is almost instantaneous and the third one, after an hour or so, becomes independent of the first two. The kinetics of the second process can be determined from the parameters of the first and third processes.

TABLE 1. Solution properties of hydroxylapatite slurries at $25^{\circ} \mathrm{C}$.

\begin{tabular}{|c|c|c|c|c|c|c|c|}
\hline \multirow{2}{*}{$\begin{array}{c}\text { Expt. } \\
\text { designation }\end{array}$} & \multirow{2}{*}{$\mathrm{pH}$} & \multirow{2}{*}{$\begin{array}{c}{\left[\mathrm{Ca}^{2+}\right]} \\
\operatorname{mol~L}\end{array}$} & \multirow{2}{*}{$\begin{array}{c}{\left[\mathrm{PO}_{4}{ }^{3-}\right]} \\
\mathrm{mol} \mathrm{L}{ }^{-1} \times 10^{4}\end{array}$} & \multirow{2}{*}{$\begin{array}{c}K_{s}^{\mathrm{a}} \\
\left(\mathrm{Ca}^{2+}\right)^{5}\left(\mathrm{PO}_{4}^{3-}\right)^{3} \\
\left(\mathrm{OH}^{-}\right) \times 10^{59}\end{array}$} & \multirow{2}{*}{$\begin{array}{c}\text { Slurry } \\
\text { density } \\
\text { g/L }\end{array}$} & \multicolumn{2}{|c|}{$\mathrm{i}_{o}{ }^{\mathrm{b}} \mathrm{cpm} / \mathrm{mL}$} \\
\hline & & & & & & ${ }^{45} \mathrm{Ca}$ & ${ }^{32} \mathrm{P}$ \\
\hline IE10 & 6.940 & 0.667 & 0.734 & 7.39 & 7.212 & 25611 & 10194 \\
\hline IE11 & 6.718 & 0.795 & 0.954 & 1.64 & 3.334 & 34425 & 17726 \\
\hline IE15 & 6.409 & 1.487 & 2.144 & 3.26 & 4.388 & 26899 & 15011 \\
\hline IE9 & 6.185 & 1.921 & 3.763 & 1.56 & 7.352 & 18996 & 12694 \\
\hline IE14 & 5.817 & 3.498 & 6.214 & 0.27 & 7.065 & 56415 & 39992 \\
\hline IE8 & 5.766 & 4.190 & 7.980 & 0.50 & 6.276 & 25480 & 12610 \\
\hline IE13 & 5.640 & 7.469 & 14.39 & 3.13 & 8.193 & 56212 & 41783 \\
\hline
\end{tabular}

a The activity products were used to calculate this constant [10].

${ }^{\mathrm{b}} i_{o}$ is the initial concentration of the radioactive ion. 


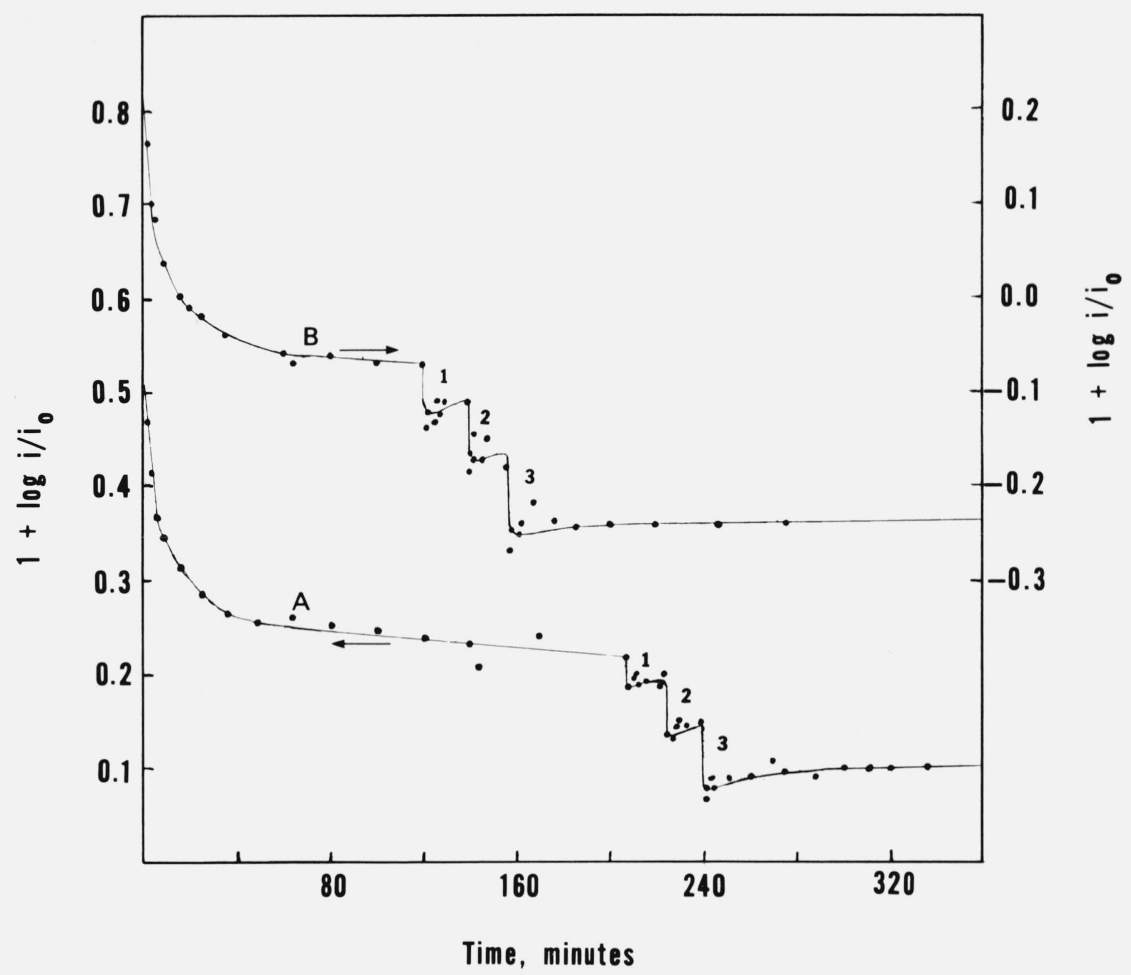

Figure 1. Exchange kinetics of ${ }^{45} \mathrm{Ca}^{2+}$ with Hydroxylapatite at $25^{\circ} \mathrm{C}$.

$\mathrm{A}$ and $\mathrm{B}$ refer to experimental runs IE 14 and IE 15 respectively. 1, 2, and 3 refer to the first, second and third dilutions.

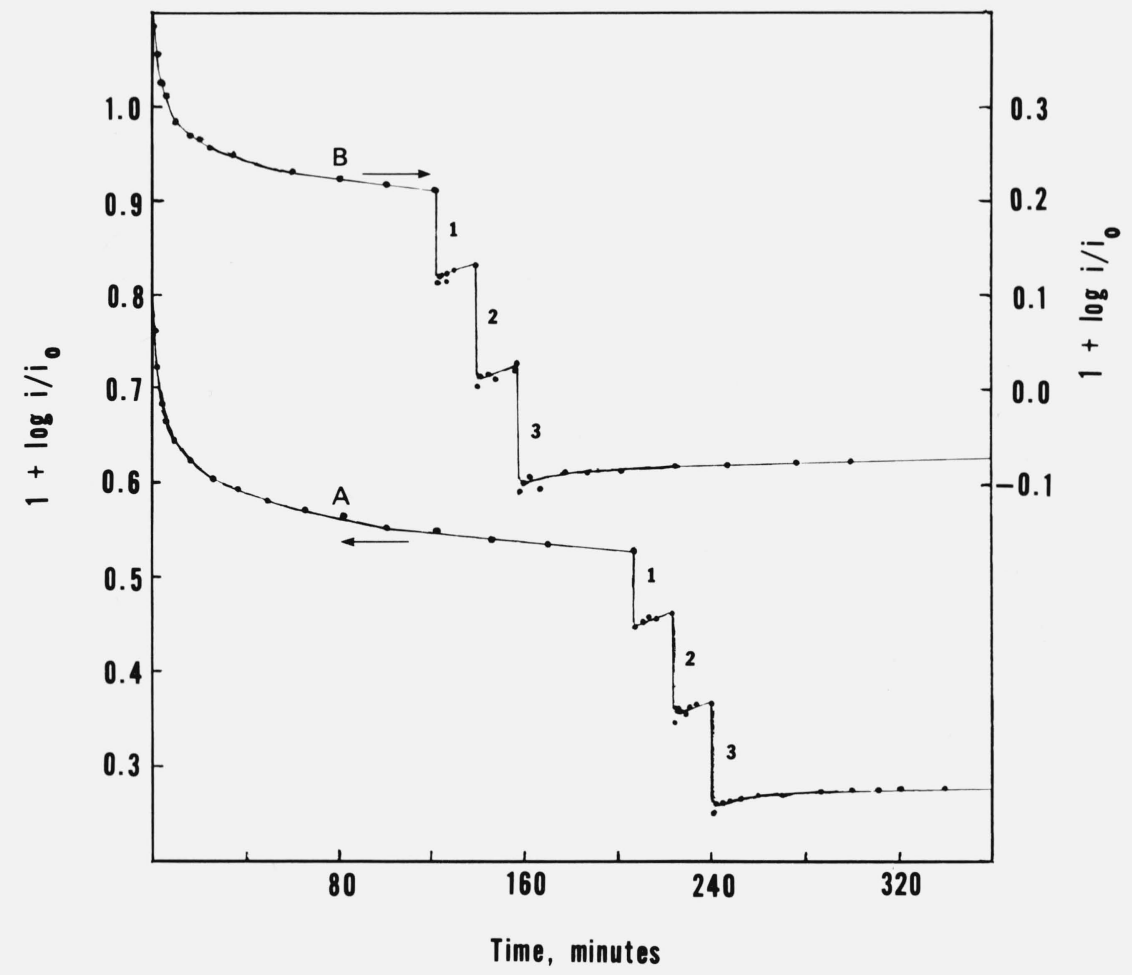

Figure 2. Exchange kinetics of ${ }^{32} \mathrm{PO}_{4}{ }^{3-}$ with Hydroxylapatite at $25^{\circ} \mathrm{C}$.

A and B refer to experimental runs IE 14 and IE15 respectively. 1, 2, and 3 refer to the first, second and third dilutions. 
The overall radioisotopic exchange mechanism may be represented as:

Satd. Soln. $\stackrel{k_{h}}{\rightleftharpoons}$ Hydration $\stackrel{R}{\rightleftharpoons}$

$$
\underset{\text { Layer }}{\stackrel{k}{c r}} \stackrel{\text { Recrystallization }}{\rightarrow}
$$

where $k_{h}, R$ and $k_{c r}$ are rate constants. The first process is almost instantaneous and, therefore, $k_{h}$ is immeasurably small and cannot be determined. The two other constants, $R$ and $k_{c r}$ can be determined by our treatment.

Recrystallization and intracrystalline diffusion. The total concentration of calcium and phosphate ions remains constant in a saturated solution at equilibrium. The dissolution of smaller crystals and the growth of bigger ones may, therefore, irreversibly remove radioactive ions from the solution. Strictly speaking, the mechanism of this slow depletion of radioactive ions is primarily due to recrystallization and not due to intracrystalline diffusion, although the effect may appear the same. The extent of the recrystallization process should be rather small since the rate of loss of radioactivity during this period is small and there usually is no discernible change in the surface area of hydroxylapatite.

This is not an equilibrium process and, therefore, the McKay equation [14] cannot be applied. It seems reasonable to assume that the rate of loss of radioactivity is directly proportional to the area of the exposed surface, $S$, or the slurry density, $D$, of hydroxylapatite and the concentration of radioactive ions, $i$, present in the solution and, therefore,

$$
-\frac{d i}{d t}=k_{c r} D i
$$

where $k_{c r}$ is the rate constant for the recrystallization process. Since $S$ remains constant, eq (1) can be integrated as follows:

$$
\ln i=-k_{c r} D t+\text { const. }
$$

The constant may be evaluated from the initial condition: when $t=o, i=i_{c r}$; and it is equal to $\ln i_{c r}$. Equation (2) now becomes:

$$
\ln i=-k_{c r} D t+\ln i_{c r}
$$

or

$$
\log \frac{i}{i_{o}}=-\frac{k_{c r} D t}{2.303}+\log \frac{i_{c r}}{i_{o}}
$$

where $i_{0}$ is the initial concentration of a radioactive ion. Therefore, the plot of $\log i / i_{o}$ vs $t$ should be linear and the intercept and slope should be equal to $\log i_{c r} / i_{o}$ and $k_{c r} D /$ 2.303 respectively. These constants for various experimental runs, except for IE9 and IE11 where enough data is not available for the recrystallization period, are given in table 2 together with other statistical parameters. In general, the linearity of eq (3) is fairly good and, therefore, the assumptions on which the equation is based should be reasonable.

TABLE 2. Recrystallization constants a of hydroxylapatite at $25^{\circ} \mathrm{C}$.

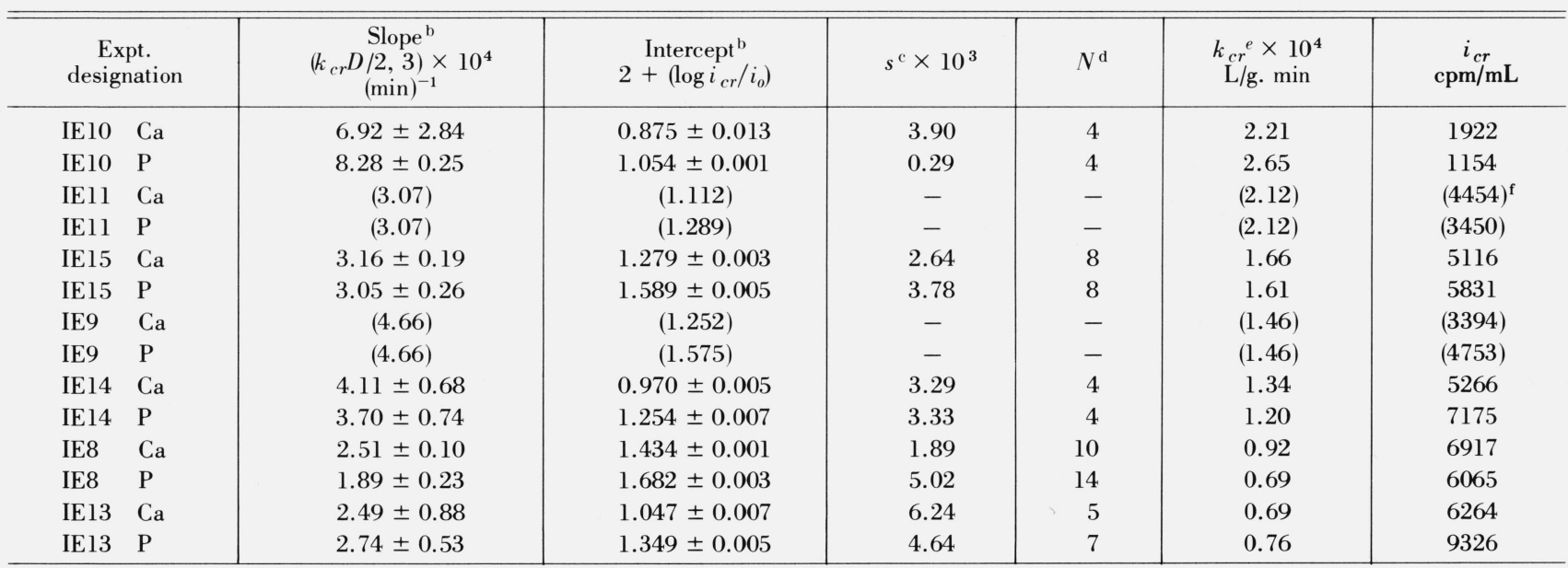

a Based on eq (3) of the text.

${ }^{\mathrm{b}}$ Least-squares estimate of the coefficient \pm its standard error.

${ }^{\mathrm{c}}$ Standard error of regression.

d Number of measurements.

e The slurry densities instead of the related surface areas of hydroxylapatite are used to normalize the values of $k_{c r}$.

${ }^{\mathrm{f}}$ Values in parenthesis are obtained from the linear dependence of $k_{c r}$ on $\mathrm{pH}$ and best estimates of $i_{c r}$ values. 


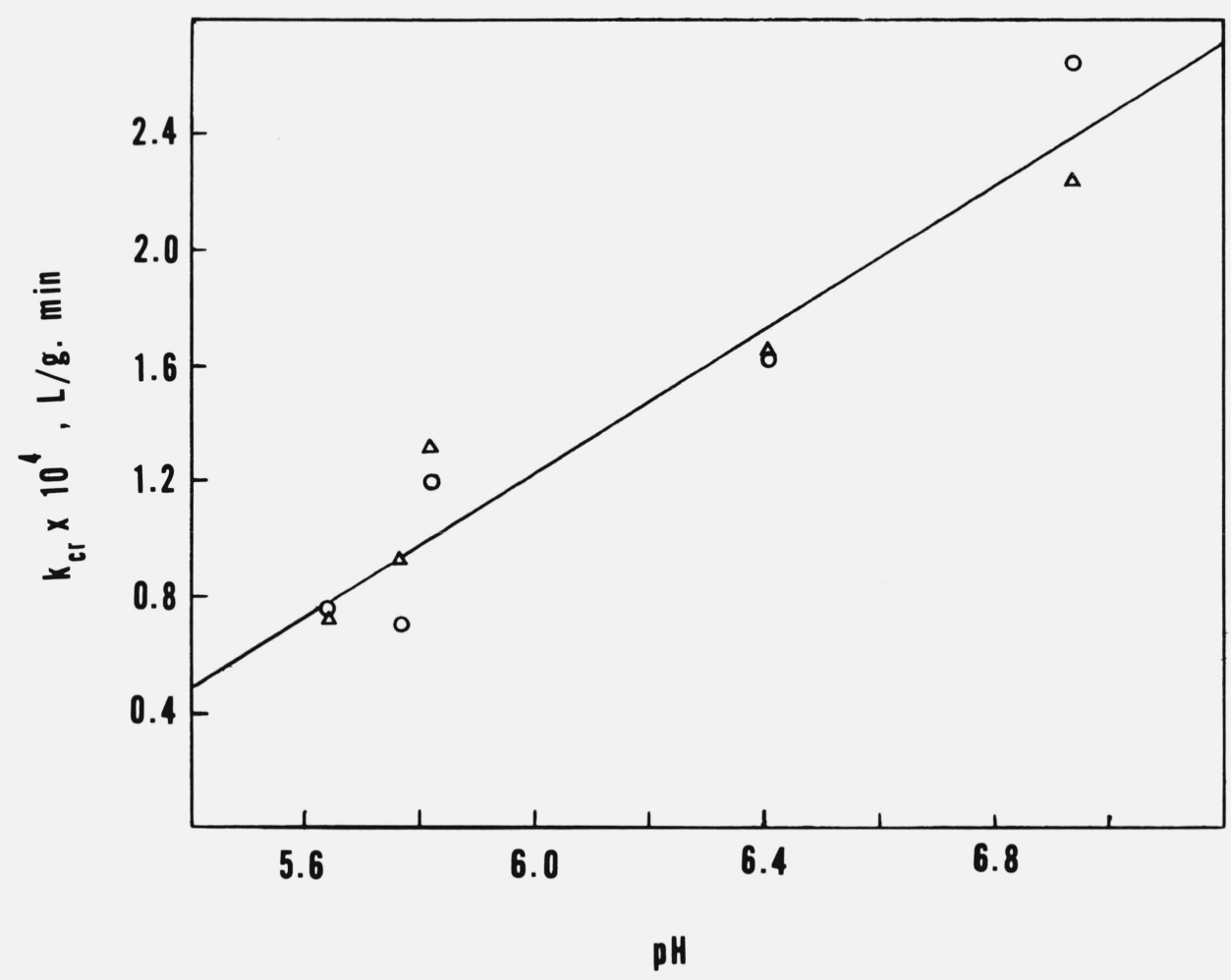

FIGURE 3. Variation of the exchange rate constant for recrystallization process with $p H$ of the solution at $25{ }^{\circ} \mathrm{C}: \triangle$ refer to ${ }^{45} \mathrm{Ca}^{2+}$ exchange and $\bigcirc$ refer to ${ }^{32} \mathrm{PO}_{4}{ }^{3-}$ exchange.

The straight line is obtained by linear regression.

The values of $k_{c r}$ and $i_{c r}$ may be obtained from the slopes and intercepts respectively (table 2 , columns 6 and 7 ). The slurry densities instead of the surface areas were used to normalize the values of $k_{\mathrm{cr}}$.

It is observed that $k_{c r}$, both for calcium and phosphate ions, is linearly related to the $\mathrm{pH}$ of solution:

$$
k_{c r}=a_{1}+b_{1} \mathrm{pH} .
$$

The plot is shown in figure 3 . Linear regression gives the values of constants: $a_{1}=-(6.18 \pm 0.82) \times 10^{-4}, b_{1}=$ $(1.23 \pm 0.13) \times 10^{-4}$ and $s=2.08 \times 10^{-5}$, where $s$ is the standard error of regression. An analysis of variance indicates [15] that, for a 95 percent confidence level, no gain is made in assigning separate linear equations to $\mathrm{Ca}^{2+}$ and $\mathrm{PO}_{4}{ }^{3-}$. For IE9 and IE11, the values of $k_{c r}$ are obtained from the constants of eq (4) and the $i_{c r}$ values are the best estimates.

Surface Layer Exchange. This exchange may be viewed as occurring between the hydration shell, $\mathrm{H}$, and the surface layer, L, of hydroxylapatite and may be represented as:

$$
\mathrm{HX}^{*}+\mathrm{LX} \rightleftharpoons \mathrm{LX}^{*}+\mathrm{HX},
$$

where $\mathrm{X}^{*}$ is a radioisotope exchanging with a normal isotope $\mathrm{X}$. Since we have assumed that the processes are separable, it is evident that the radioisotopic concentrations may be taken as $i_{e}$ at the end of the first process or at the beginning of the second one and $i_{c r}$ at the end of the second process or at the beginning of the third one. Now, applying the McKay equation, $[14,16]$ we may easily obtain that:

$$
\log \left(i-i_{c r}\right)=\log \left(i_{e}-i_{c r}\right)-\frac{R(a+b) t}{2.303 a b}
$$

where $a(\mathrm{~mol} / \mathrm{L})$ is the total concentration of exchanging ion in solution and $b(\mathrm{~mol} / \mathrm{L})$ is the concentration of ion on the surface of hydroxylapatite which is in equilibrium with one litre of the solution. The term $b$ is a composite term and may be expressed as: $b=N_{L}^{\text {calc }} D$, where $N_{L}^{\text {calc }}(\mathrm{mol} / \mathrm{g})$ is the calculated concentration of total exchangeable ion on the surface $\left(N_{L}{ }^{\text {calc }}=S / N \sigma\right.$, see footnotes to table 3$)$ and $D(\mathrm{~g} / \mathrm{L})$ is the slurry density of hydroxylapatite.

The plot of $\log \left(i-i_{c r}\right)$ vs $t$ should be linear and the intercept and slope should be equal to $\log \left(i_{e}-i_{c r}\right)$ and $R(a$ $+b) / 2.303 a b$ respectively. These constants for various 
TABLE 3. Constants associated with surface layer exchange at $25^{\circ} \mathrm{C}$.

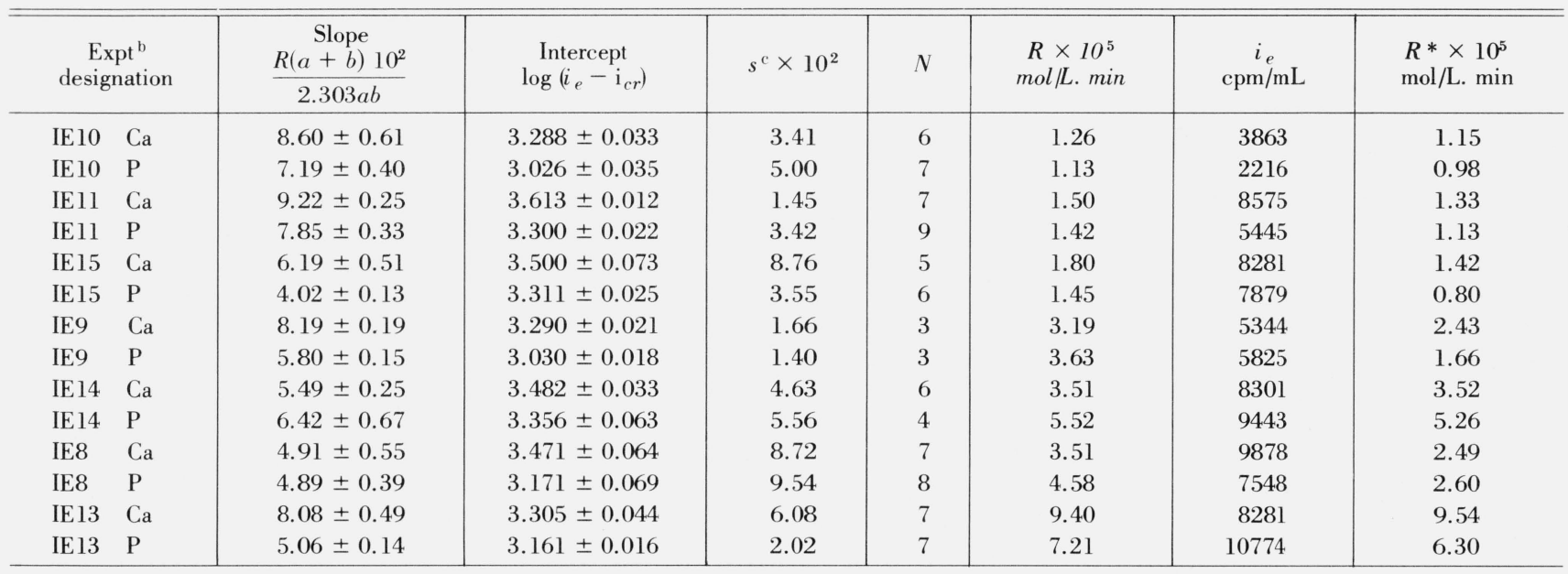

${ }^{\text {a }}$ Based on eq 5 of the text where $b=N_{L}{ }^{\text {calc }} D=S D / N \sigma$ and $N_{L}{ }^{\text {calc }}(\mathrm{mol} / \mathrm{g})$ is the calculated concentration of total exchangeable ion on the surface; $S$ is the surface area $\left(26.4 \mathrm{~m}^{2} / \mathrm{g}\right)$ and $D$ is the slurry density $(\mathrm{g} / \mathrm{L}$, Table $\mathrm{I})$ of hydroxylapatite; $N$ is the Avogadro's number and $\sigma$ is the effective area of the exchangeable ion $\left(23 \AA^{2}\right.$ for $\mathrm{Ca}^{2+}$ and $33 \AA^{2}$ for $\left.\mathrm{PO}_{4}{ }^{3-}\right)$.

${ }^{\mathrm{b}}$ All points obtained before two minutes have been neglected.

c Standard error of regression.

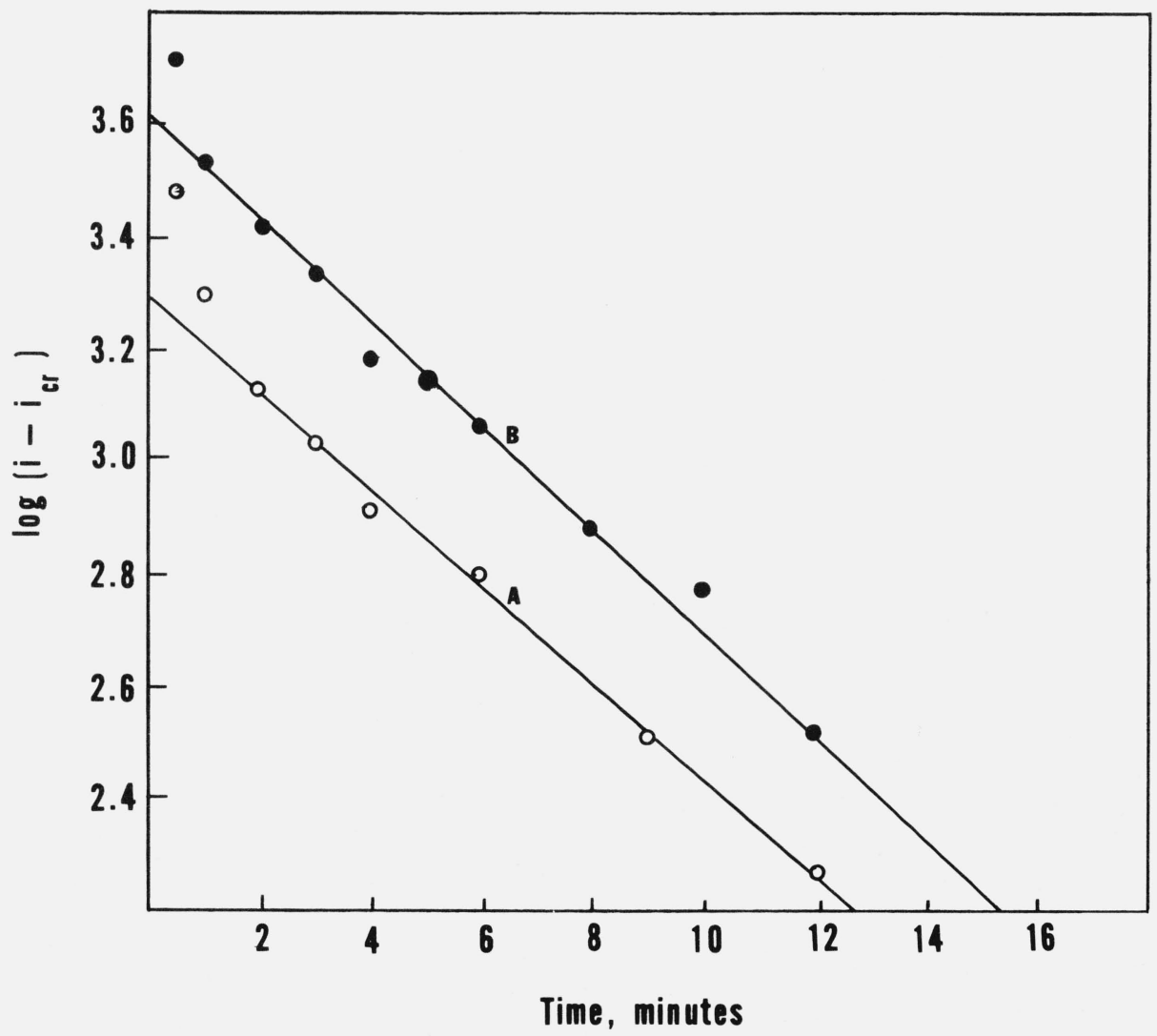

Figure 4. $\log \left(i-i_{c r}\right)$ vs time for ${ }^{45} \mathrm{Ca}^{2+}$ at $25^{\circ} \mathrm{C}$.

$A$ and B refer to experimental runs IE10 and IE11 respectively. The straight lines are obtained by linear regression. 
experimental runs are given in table 3 together with other statistical parameters and figures 4 and 5 show the plots for two runs. In general, the linearity of eq (5) is fairly good. The experimental points do not, generally, fall on the straight line (figs. 4 and 5) before two minutes have elapsed. This is, possibly, because it takes at least that much mixing time for the solution to reach uniformity after a radioactive ion is injected into it. Our analysis shows that the exchange between surface layer and hydration shell or bulk solution is complete within half an hour after which the linearity of eq 5 is not maintained. Similar equilibrium times were observed for nickelous [12, 13], cupric [12, 13] and zinc [17] ions exchanging with hydroxylapatite surface.

Radioisotopic exchange experiments at the point of zero charge [5] $(\mathrm{pH}=8.5)$ and exchange experiments with other ions [12, 13, 17] with hydroxylapatite yield effective areas of $23 \AA^{2}$ and $33 \AA^{2}$ for calcium and phosphate ions respectively. These values, together with the $\operatorname{BET}\left(\mathrm{N}_{2}\right)$ surface area of the hydroxylapatite yield the calculated concentration of a total exchangeable ion $\left(N_{L}{ }^{\text {calc }}\right)$ on the surface.
The constants, $R$ and $i_{e}$, can be derived from the slope and intercept of eq (5), respectively (table 3 , columns 6 and 7 ). It is observed that $R$, both for calcium and phosphate ions, is linearly related to the hydrogen ion concentration of solution:

$$
R=a_{2}+b_{2}\left[\mathrm{H}^{+}\right]
$$

The plot is shown in figure 6. Linear regression gives the values of constants: $a_{2}=(0.82 \pm 0.46) \times 10^{-5}, b_{2}=(0.274$ $\pm 0.037) \times 10^{-5}$ and $s=1.09 \times 10^{-5}$ where $s$ is the standard error of regression. An analysis of variance indicates [15] that, for a 95 percent confidence level, no gain is made in assigning separate linear equations to $\mathrm{Ca}^{2+}$ and $\mathrm{PO}_{4}{ }^{3-}$. The expected identity of $R$ values obtained from the exchange of either calcium or phosphate ions also demonstrates that the assumed ratio [5] (23/33) of the crosssectional areas of the two ions is reasonable.

The dependence of $R$ on $[\mathrm{H}]^{+}$in eq $(5)$ does not necessarily imply that the intercepts should also be so dependent. In

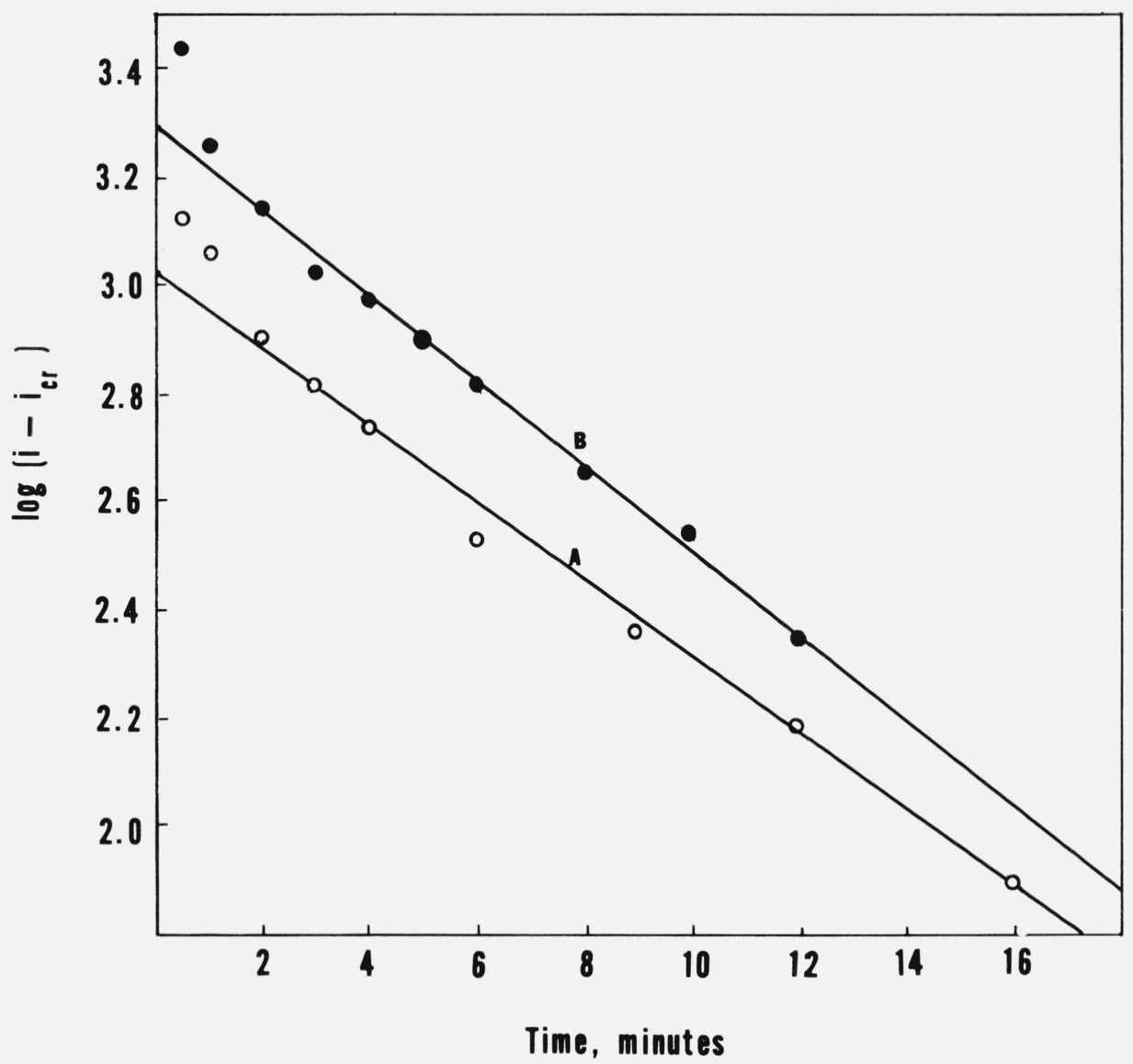

Figure 5. $\quad \log \left(i-i_{\text {cr }}\right)$ vs time for ${ }^{32} \mathrm{PO}_{4}{ }^{3-}$.

$\mathrm{A}$ and $\mathrm{B}$ refer to experimental runs IE10 and IE11 respectively. The straight lines are obtained by linear regression. 
fact, a casual perusal of the intercept values (table 3, column 3 ) shows that they are fairly constant $3.30 \pm 0.15$.

Capacities of Hydration Shell and Surface Layer. The capacity of the hydration shell $\left(N_{H}\right)$ can be easily derived as:

$$
N_{H}=\frac{a}{D}\left(\frac{i_{o}-i_{e}}{i_{e}}\right),
$$

where symbols have their usual designations. The total experimental capacity of hydration shell and surface layer is:

$$
\left(N_{H}+N_{L}\right)=\frac{a}{D}\left(\frac{i_{o}-i_{c r}}{i_{c r}}\right) .
$$

The experimental capacity of the surface layer $\left(N_{L}\right)$ is the difference of eqs (8) and (7)

$$
N_{L}=\frac{a}{D}\left[\left(\frac{i_{o}-i_{c r}}{i_{c r}}\right)-\left(\frac{i_{o}-i_{e}}{i_{e}}\right)\right] .
$$

This can also be obtained from the following basic condition of equilibrium of a radioisotope in various reversible pools: $\frac{[\text { Bulk Solution] }}{\mathrm{M}^{*}{ }_{\text {Soln }}}=\frac{[\text { Hydration Layer }]}{\mathrm{M}^{*}{ }_{\mathrm{H}}}$ $=\frac{[\text { Surface Layer }]}{\mathrm{M}^{*}{ }_{\mathrm{L}}}$

where the numerators respectively designate the concentrations of total exchangeable ions in solution, in hydration layer and on hydroxylapatite surface, and the denominators give the respective concentrations of radioactive ion $(M *)$ in various pools. In the present case eq (10) may be represented as:

$$
\frac{a}{i_{c r}=\frac{a\left(\frac{i_{o}-i_{e}}{i_{e}}\right)}{i_{c r}\left(\frac{i_{o}-i_{e}}{i_{e}}\right)}}=\frac{D N_{L}}{\left[\left(i_{o}-i_{c r}\right)-i_{c r}\left(\frac{i_{o}-i_{e}}{i_{e}}\right)\right]} .
$$

It is evident that eq (11) is identical to eq (9).

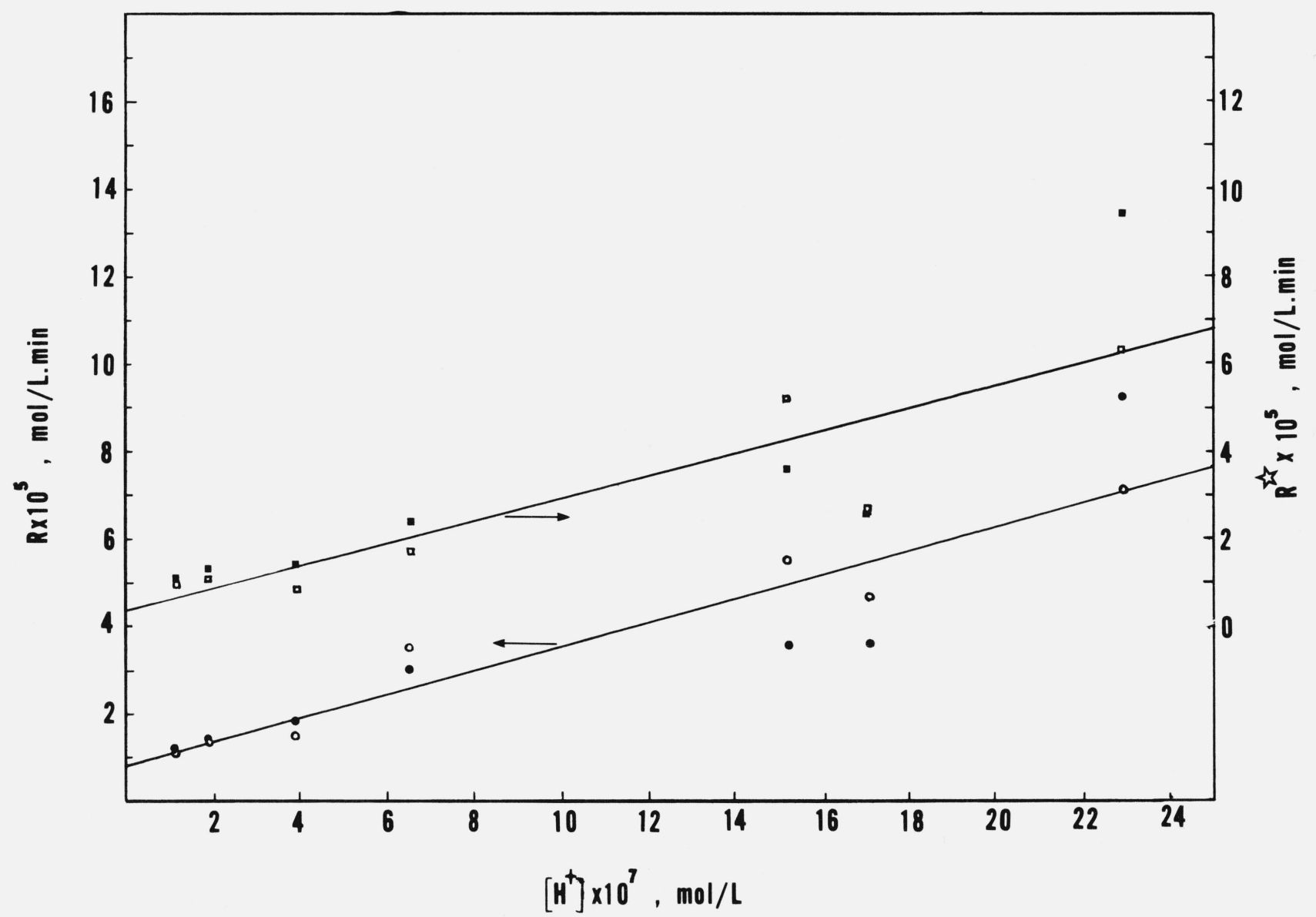

FIGURE 6. Variation of exchange rate constants for surface layer with $\left[\mathrm{H}^{+}\right]$of the solution at $25^{\circ} \mathrm{C}$ : The straight lines are obtained by linear regression. 
The values of the capacities of various pools for different runs are given in table 4 . The various capacities do not change very much with hydrogen ion concentration up to $\mathrm{pH}=6$; the change is continuous and dramatic after that. One such plot is shown in figure 7 . It may be that the variation $\left\{N_{(H \text {, or } L \text { or } H+D}\right.$ vs $\left.\left[\mathrm{H}^{+}\right]\right\}$is parabolic. The data is, however, scarce and scattered, and other possibilities cannot be ignored. The scattering of data may be related to the variable contamination of the surface layers of hydroxylapatite $[10,11]$. Probably, the surface concentrations of constituent ions are best obtained at the point of zero charge of the substrate [5].

TABLE 4. Capacities of hydration shell and surface layer at $25^{\circ} \mathrm{C}$.

\begin{tabular}{|c|c|c|c|c|c|c|c|}
\hline \multirow[b]{2}{*}{$\begin{array}{c}\text { Expt. } \\
\text { designation }\end{array}$} & \multicolumn{3}{|c|}{$\mathrm{Ca}^{2+}$ capacity ${ }^{\mathrm{a}}, \mathrm{mol} / \mathrm{g}$} & \multicolumn{3}{|c|}{$\mathrm{PO}_{4}{ }^{3-}$ capacity ${ }^{\mathrm{a}}, \mathrm{mol} / \mathrm{g}$} & \multirow[b]{2}{*}{$\begin{array}{c}\left(N_{L}+N_{H}\right) \\
\text { for } \mathrm{Ca}^{2+} \\
\text { divided by } \\
\left(N_{L}+N_{H}\right) \\
\text { for } \mathrm{PO}_{4}{ }^{3-}\end{array}$} \\
\hline & $\begin{array}{c}\begin{array}{c}N_{H}= \\
{\left[\mathrm{Ca}^{2+}\right][B]}\end{array} \\
\begin{array}{c}S \\
\times 10^{4}\end{array}\end{array}$ & $\begin{array}{c}\begin{array}{c}N_{L}= \\
{\left[\mathrm{Ca}^{2+}\right][A-B]}\end{array} \\
\begin{array}{l}S \\
\times 10^{4}\end{array}\end{array}$ & $\begin{array}{l}\left(N_{L}+N_{H}\right) \\
\quad \times 10^{4}\end{array}$ & $\begin{array}{c}\begin{array}{c}N_{H}= \\
{\left[\mathrm{PO}_{4}{ }^{3-}\right][B]}\end{array} \\
\times S \\
\times 10^{4}\end{array}$ & $\begin{array}{c}N_{L}= \\
\frac{\left[\mathrm{PO}_{4}{ }^{3-}\right][A-B]}{S} \\
\times \quad 10^{4}\end{array}$ & $\underset{10^{4}}{\left(N_{L}+N_{H}\right) \times}$ & \\
\hline IE 10 & 0.521 & 0.619 & 1.140 & 0.366 & 0.431 & 0.797 & 1.430 \\
\hline IE11 & 0.719 & 0.886 & 1.605 & 0.645 & 0.539 & 1.184 & 1.356 \\
\hline IE15 & 0.762 & 0.681 & 1.443 & 0.442 & 0.327 & 0.769 & 1.876 \\
\hline IE9 & 0.668 & 0.534 & 1.201 & 0.604 & 0.252 & 0.855 & 1.405 \\
\hline IE14 & 2.870 & 1.939 & 4.809 & 2.845 & 1.178 & 4.023 & 1.195 \\
\hline IE8 & 1.054 & 0.738 & 1.792 & 0.853 & 0.519 & 1.372 & 1.306 \\
\hline IE 13 & 5.277 & 1.993 & 7.269 & 5.055 & 1.057 & 6.112 & 1.189 \\
\hline \multicolumn{7}{|c|}{ Mean \pm standard deviation } & $1.39 \pm 0.23$ \\
\hline
\end{tabular}

${ }^{a} A=\left(i_{o}-i_{c r}\right) / i_{c r}$ and $B=\left(i_{o}-i_{e}\right) / i_{e} . N_{H}$ and $N_{L}$ are the capacities of the hydration shell and surface layer respectively.

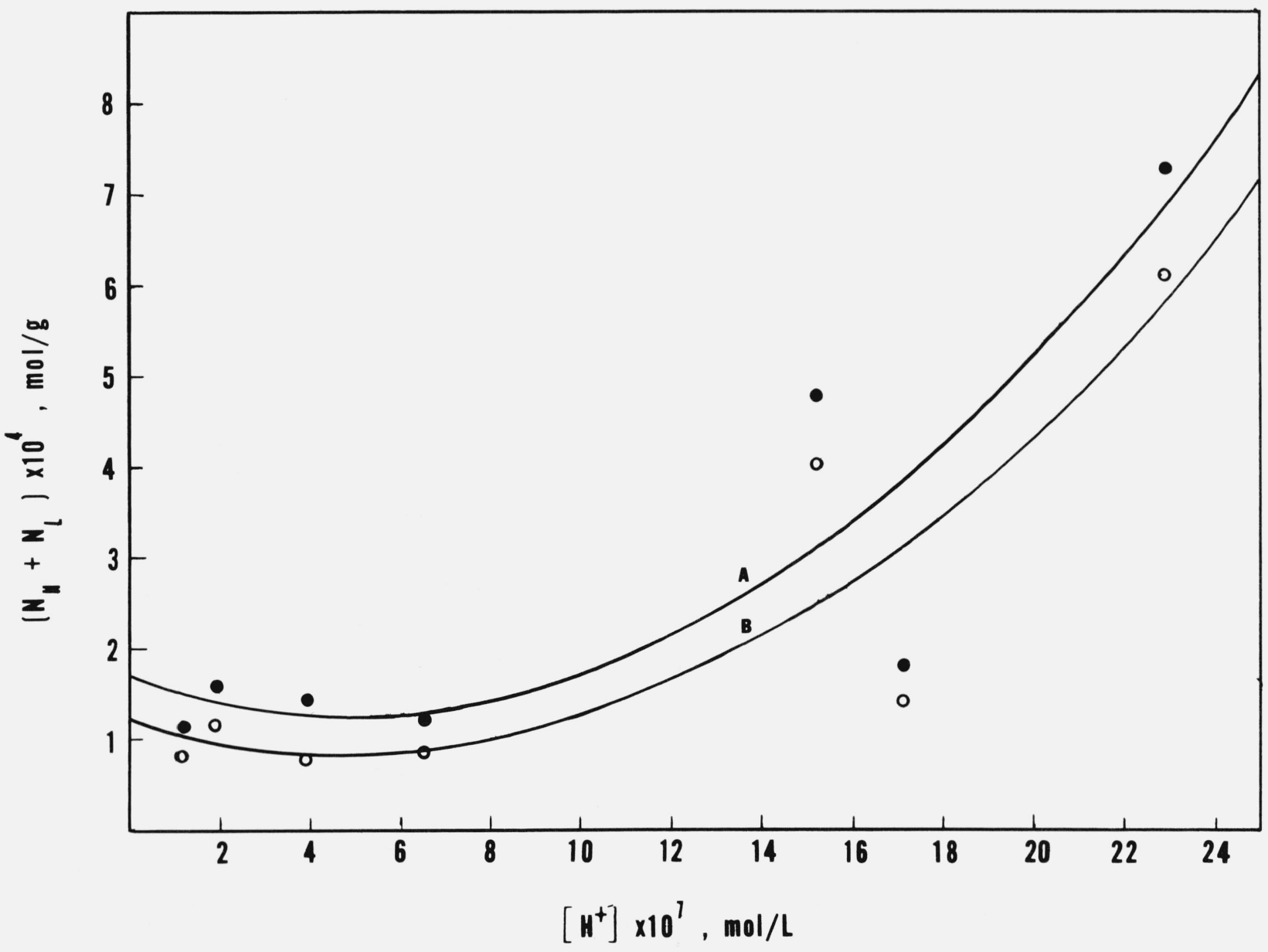

Figure 7. Variation of total capacity of reversible pools $\left(\mathrm{N}_{\mathrm{H}}+\mathrm{N}_{\mathrm{L}}\right)$ with $\left[\mathrm{H}^{+}\right]$of the solution at $25{ }^{\circ} \mathrm{C}: \mathrm{refers} \mathrm{to}^{\mathrm{Ca}} \mathrm{a}^{2+}$ and $\bigcirc$ refers to $\mathrm{PO}{ }_{4}{ }^{3-}$. The curves are best parabolic fits ${ }^{18}$. 
The mean of the ratios of the total capacities (hydration shell + surface layer) of calcium ions to phosphate ions is 1.39 (table 4 , last column). The theoretical ratio is $33 / 23=$ 1.43. The two values agree within the limits of experimental error.

By substituting the experimental value of the total capacity of surface layer, $N_{L}$ (table 4 , columns 3 and 6), for $N_{L}{ }^{\text {calc }}$ in the slope of eq (5) (table 3, column 2), the true value of the surface exchange rate constant $\left(R^{*}\right)$ can be calculated (table 3 , column 8). The values of $R^{*}$ are, however, not much different from those of $R$. The rate constant $R^{*}$, also, varies linearly with $\left[\mathrm{H}^{+}\right]$(fig. 6). Linear regression yields the values of constants: intercept $=(0.35 \pm 0.59) \times 10^{-5}$, slope $=$ $(0.260 \pm 0.047) \times 10^{-5}$ and standard error of regression $=$ $1.40 \times 10^{-5}$.

Dilution Effect. The effect of dilution on the concentration of radioactive ions, without changing the concentrations (or the $\mathrm{pH}$ ) of nonradioactive components of the solution, may be divided into reversible and irreversible parts:

$$
i^{\mathrm{It}}=i_{r}^{\mathrm{I}}-\left(i_{c r}-i^{t}\right),
$$

where $i^{\text {It }}$ is equilibrium concentration of a radioactive ion, corrected for the irreversibly removed ions, after the first dilution at a given time, $i_{r}{ }^{\mathrm{I}}$ is the equilibrium concentration for reversibly exchanging ions after the first dilution, $i_{c r}$ has already been defined, and $i^{t}$ is the concentration of radioactive ion present in the solution after a given recrystallization time (eq (3), table 2 ).
The constant $i_{r}$ I can be obtained from the following equilibrium condition:

$\frac{[\text { Solution }]_{1}{ }^{i}}{{\text { Solution }]_{1}}^{f}}=\frac{[\text { Surface Layer }]_{1}{ }^{i}}{{\text { Surface Layer }{ }_{1}}^{f}}$

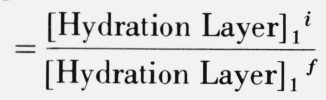

where $\left({ }_{1}{ }^{i}\right)$ refers to the beginning and $\left({ }_{1}{ }^{f}\right)$ to the end of the first dilution. The concentration of a radioactive ion after the dilution in any one of the pools may be easily calculated from the appropriate material balance equation. Consideration of any one equality between the three terms in eq (13) is sufficient to derive $i_{i}$. We shall derive it from the equality between the first and second terms, although it may be easier to derive from the equality between the first and third terms. Considering the equality between the first and second terms, eq (13) may be physically represented as:

$$
\frac{i_{c r}}{i_{r} \mathrm{I}}=\frac{\frac{V_{1}{ }^{i}}{N_{L} D}\left[\left(i_{o}-i_{c r}\right)-i_{c r}\left(\frac{i_{o}-i_{e}}{i_{e}}\right)\right]}{\frac{V_{1}{ }^{f}}{N_{L} D}\left[\left(\frac{V_{1}{ }^{i}}{V_{1}{ }^{f}} i_{o}-i_{r}{ }^{\mathrm{I}}\right)-i_{r}{ }^{\mathrm{I}}\left(\frac{i_{o}-i_{e}}{i_{e}}\right) \frac{V_{1}{ }^{i}}{V_{1}{ }^{f}}\right]},
$$

where $V_{1}{ }^{i}$ is volume of the solution before the first dilution

\begin{tabular}{|c|c|c|c|c|c|c|c|c|c|c|}
\hline \multirow{4}{*}{\multicolumn{2}{|c|}{$\begin{array}{c}\text { Expt. } \\
\text { designation }\end{array}$}} & \multirow{4}{*}{$\frac{V_{1}{ }^{i}}{V_{1}{ }^{f}}$} & \multirow{2}{*}{\multicolumn{2}{|c|}{$\begin{array}{c}\text { First dilution } \\
{\left[\begin{array}{c}\left.i_{r}^{\mathrm{I}}-\left(i_{c r}-i^{\mathrm{t}}\right)\right]^{\mathrm{a}} \\
\mathrm{epm} / \mathrm{mL}\end{array}\right.}\end{array}$}} & \multirow{2}{*}{\multicolumn{3}{|c|}{ Second dilution }} & \multirow{2}{*}{\multicolumn{3}{|c|}{ Third dilution }} \\
\hline & & & & & & & & & & \\
\hline & & & \multirow[t]{2}{*}{ Expt } & \multirow[t]{2}{*}{ Calcd. } & \multirow{2}{*}{$\frac{V_{2}{ }^{i}}{V_{2}^{f}}$} & \multicolumn{2}{|c|}{$\mathrm{i}_{r}^{\mathrm{II}}, \mathrm{cpm} / \mathrm{mL}$} & \multirow{2}{*}{$\frac{V_{3}^{i}}{V_{3}^{f}}$} & \multicolumn{2}{|c|}{$i_{r}^{{ }_{r}^{I I I} \mathrm{cpm} /}$} \\
\hline & & & & & & Expt. & Calcd. & & Expt. & Calcd. \\
\hline IE10 & $\mathrm{Ca}$ & $505 / 705$ & 1685 & 1623 & $645 / 945$ & 1540 & 1559 & $890 / 1290$ & 1370 & 1476 \\
\hline IE10 & $\mathrm{P}$ & “ & 950 & 933 & “ & 850 & 881 & “ & 720 & 816 \\
\hline IE11 & $\mathrm{Ca}$ & $425 / 625$ & 4075 & 4088 & $571 / 871$ & 3575 & 3744 & $817 / 1217$ & 3200 & 3345 \\
\hline IE11 & $\mathrm{P}$ & “ & 3050 & 3072 & , & 2390 & 2709 & “ & 1950 & 2320 \\
\hline IE 15 & $\mathrm{Ca}$ & $490 / 690$ & 4140 & 4090 & $640 / 940$ & 3760 & 3717 & $890 / 1290$ & 3350 & 3294 \\
\hline IE15 & $\mathrm{P}$ & “ & 4310 & 4194 & “ & 3480 & 3541 & “ & 2800 & 2904 \\
\hline IE9 & $\mathrm{Ca}$ & $534.5 / 834.5$ & 2750 & 2789 & $798.5 / 1398.5$ & 2375 & 2379 & - & - & - \\
\hline IE9 & $\mathrm{P}$ & “ & 3625 & 3636 & “ & 2850 & 2721 & - & - & - \\
\hline IE14 & $\mathrm{Ca}$ & $500 / 700$ & 4350 & 4419 & $650 / 950$ & 3950 & 4206 & $900 / 1300$ & 3300 & 3938 \\
\hline IE14 & $\mathrm{P}$ & “ & 5400 & 5885 & . & 4250 & 5374 & “ & 3300 & 4789 \\
\hline IE8 & $\mathrm{Ca}$ & $662 / 1062$ & 5120 & 5071 & - & - & - & - & - & - \\
\hline IE8 & $\mathrm{P}$ & “ & 4225 & 4090 & - & - & - & - & - & - \\
\hline IE 13 & $\mathrm{Ca}$ & $490 / 690$ & 5200 & 5502 & $645 / 945$ & 4550 & 5170 & $900 / 1300$ & 3675 & 4765 \\
\hline IE 13 & $\mathrm{P}$ & “ & 7000 & 7744 & $“$ & 5350 & 6900 & $“$ & 4050 & 5990 \\
\hline
\end{tabular}
and $V_{1}{ }^{f}$ after the dilution (table 5, column 2). A simple

TABLE 5. Radioactive exchange and dilution effect at $25^{\circ} \mathrm{C}$.

${ }^{a}$ The recrystallization times (in minutes) in order of experimental runs are: 85, 35, 221, 84, 141, 245 and 143. 
manipulation of eq (14) yields:

$$
i_{r}{ }^{\mathrm{I}}=\frac{i_{o} i_{c r}}{\left[i_{o}+i_{c r}\left(\frac{V_{1}{ }^{f}}{V_{1}{ }^{i}}-1\right)\right]} .
$$

The same result is also obtained if no hydration layer is assumed. The various terms of eq (15) are known and, therefore, $i_{r}{ }^{\mathrm{I}}$ can be calculated.

The amount of radioactive ion $\left(i^{t}\right)$, present in the solution after a given recrystallization time, may be calculated from eq (3) (slopes and intercepts are given in table 2). Therefore, the contribution of the irreversible component, $\left(i_{c r}-i^{\dagger}\right)$, can be determined.

The corrected values $\left(i^{i t}\right)$ of the equilibrium concentrations of an ion after the first dilutions at any given time can now be calculated from eq (12) and are presented in table 5 (column $4)$. The experimental values are the best estimates from the enlarged graphs $(i$ versus $t)$ at a given time (generally, the time when maxima are attained and this is the time for which $i^{t}$ is calculated). The agreement between the experimental and calculated values of $i^{\text {It }}$ is very good, considering the scattering of the experimental data on one hand and the limitations of theoretical treatment on the other.

It is difficult to apply a correction (due to the irreversible removal of ions) to the equilibrium concentration of an ion after the second or third dilution, since it is not possible to identify the experimental quantities with theoretical terms. And, therefore, no attempt is made to apply the correction term for second and third dilutions.

The concentration of a radioactive ion after the second dilution, considering the exchange as completely reversible, may be best calculated from the following equality:

$\underline{\text { [Solution }_{2}}{ }^{i}$

${\text { [Solution }]_{2}}^{f}$

$$
=\frac{[\text { Hydration }+ \text { Surface Layer }]_{2}{ }^{i}}{[\text { Hydration }+ \text { Surface Layer }]_{2}{ }^{f}}
$$

The concentrations in the second term can, again, be calculated from the material balance equation and eq (16) may be represented as:

$$
\frac{i^{\mathrm{It}}}{i_{r}{ }^{\mathrm{II}}}=\frac{V_{2}{ }^{i}\left[i_{o}-\frac{V_{1}{ }^{f}}{V_{1}{ }^{i}} i^{\mathrm{It}}\right]}{V_{2}{ }^{f}\left[\frac{V_{2}{ }^{i}}{V_{2}{ }^{f}} i_{o}-\frac{V_{1}{ }^{f}}{V_{1}{ }^{i}} i_{r}{ }^{\mathrm{II}}\right]},
$$

where the new symbols have designations analogous to those

constituting eq (14). A simplificatiion of eq (17) gives:

$$
i_{r}{ }^{\mathrm{II}}=\frac{i_{0} i^{\mathrm{It}}}{\left[i_{0}+i^{\mathrm{It}} \frac{V_{1}{ }^{f}}{V_{1}{ }^{i}}\left(\frac{V_{2}{ }^{f}}{V_{2}{ }^{i}}\right)\right]}
$$

Similarly, the concentration of a radioactive ion after the third dilution, considering the exchange as completely reversible, may be calculated as:

$$
i_{r}{ }^{\mathrm{III}}=\frac{i_{o} i_{r}{ }^{\mathrm{II}}}{\left[i_{o}+i_{r}{ }^{\mathrm{II}} \frac{V_{1}{ }^{f} V_{2}{ }^{f}}{V_{1}{ }^{i} V_{2}{ }^{i}}\left(\frac{V_{3}{ }^{f}}{V_{3}{ }^{i}}-1\right)\right]}
$$

The values of $i_{r}{ }^{\mathrm{II}}$ and $i_{r}{ }^{\mathrm{III}}$ are given in table 5 . The agreement between the calculated and experimental values of $i_{r}{ }^{I I}$ and $i_{r}{ }^{I I I}$ appears reasonable for most runs. If the error due to the irreversible removal of radioactive ion from the solutions could be estimated, a better agreement probably would result.

A better correlation for the exchange experiments, conducted at various hydrogen ion concentrations, might result if the incongruent dissolution of hydroxylapatite due to the variability in the composition of the surface layers were overcome by rejecting the initially equilibrated solutions two or three times before starting the experimental runs.

\section{Glossary}

$a$

$b$

$D$

$i$ or $i^{t}$

$i_{c r}$

$i_{e}$

${ }_{r}^{\mathrm{I}}, i_{r}^{\mathrm{II}}, i_{r}^{\mathrm{III}}$

$i_{r}^{\mathrm{I}}, i_{r}{ }^{\mathrm{II}}, i_{r}{ }^{\mathrm{III}}=$ equilibrium concentrations $(\mathrm{cpm} / \mathrm{mL})$ for reversibly exchanging radioactive ions after first, second and third dilutions respectively, 
$i^{\mathrm{It}} \quad=$ equilibrium concentration $(\mathrm{cpm} / \mathrm{mL})$ of radioactive ion, corrected for the irreversibly removed ions, after first dilution at time " $t$ ",

$k_{c r} \quad=$ rate constant $(\mathrm{L} / \mathrm{g} . \mathrm{min})$ of exchangeable ion for recrystallization process,

$N_{H} \quad=$ capacity $(\mathrm{mol} / \mathrm{g})$ of hydration shell for exchangeable ion,

$N_{L}, N_{L}{ }^{\text {calc }}=$ experimental and calculated capacity $(\mathrm{mol} /$ g) of total exchangeable ion on surface,

$R, R^{*} \quad=$ experimental and "true" surface exchange rate constant $(\mathrm{mol} / \mathrm{L}$. $\mathrm{min})$ of ion,

$S \quad=$ surface area $\left(\mathrm{m}^{2} / \mathrm{g}\right)$ of hydroxylapatite,

$V_{1}{ }^{i}, V_{2}{ }^{i}, V_{3}{ }^{i}=$ initial volumes $(\mathrm{mL})$ of solutions before first, second and third dilutions respectively,

$V_{1}{ }^{f}, V_{2}{ }^{f}, V_{3}{ }^{f}=$ final volumes $(\mathrm{mL})$ of solutions after first, second and third dilutions respectively.

\section{References}

[1] Weikel, J. H., Neuman W. F., and Feldman, I., J. Am. Chem. Soc., 76, 5202 (1954).

[2] Neuman, W. F., and Neuman, M. W., The Chemical Dynamics of Bone Mineral, University of Chicago, Chicago, Ill., 1958.

[3] Pak, C. Y. C., and Bartter, F. C., Biochim. Biophys. Acta, 141, 401 (1967).
[4] Avnimelech, Y., Israel J. Chem., 6, 375 (1968).

[5] Kukura, M., Bell, L. C., Posner, A. M., and Quirk, J. P., J. Phys. Chem., 76, 900 (1972).

[6] Kukura, M., Bell, L. C., Posner, A. M., and Quirk, J. P., Soil Sci. Amer. Proc., 37, 364 (1973).

[7] Loebenstein, W. V., J. Coll. \& Interface Sci., 36, 234 (1971).

[8] Zimens, K. Arkiv for Kemi (Mineralogi O. Giologi), 20A, 1 (1945).

[9] Edgington, D. N., Radiat. Res., 25, 257 (1965).

[10] Avnimelech, Y., Moreno, E. C., and Brown, W. E., Solubility and surface properties of finely divided hydroxyapatite, J. Res. Nat. Bur. Stand. (U.S), 77A, (Phys. and Chem.), No. 1, 149-155 (Jan.Feb. 1973).

[11] Smith, A. N., Posner, A. M., and Quirk, J. P., J. Colloid Interface Sci., 48, 442 (1974).

[12] Misra, D. N., Bowen, R. L., and Wallace, B. M., J. Colloid Interface Sci., 51, 36 (1975).

[13] Misra, D. N., and Bowen, R. L., J. Biomed. Matls. Res., 12, 505 (1978).

[14] McKay, H. A. C., Nature, 142, 997 (1938).

[15] Afifi, A. A., and Azen, S. P., Statistical Analysis: A Computer Oriented Approach, (Academic Press, Inc., New York, N.Y., 1972), pp. 108-113, 146-151. (Thanks are due to H. Argentar who pointed out this method and reference to the author.)

[16] Frost, A. A., and Pearson, R. G., Kinetics and Mechanism, (John Wiley and Sons, Inc., New York, N.Y., 1953), p. 179.

[17] Misra, D. N., and Bowen, R. L., to be published.

[18] Mood, A. M., and Graybill, F. A., Introduction to the Theory of Statistics, (2nd ed.), (McGraw Hill Book Co., New York, N.Y. 1963). 